\title{
El aprovechamiento del carpincho (Hydrochoerus hydrochaeris) en los sitios Cerro Aguará y Barrancas del Paranacito (departamento General Obligado, provincia de Santa Fe)
}

\section{Ana C. Servin}

(D) https://orcid.org/0000-0001-7358-6127

Escuela de Antropología, Facultad de Humanidades y Artes, Universidad Nacional de Rosario (UNR). Entre Ríos 758 (CP S2000CRN), Rosario, Santa Fe, Argentina. E-mail: anaceciliaservin@gmail.com

\section{Resumen}

En el presente trabajo se exponen los resultados de la revisión del registro arqueofaunístico correspondiente a carpincho (Hydrochoerus hydrochaeris) de los sitios Cerro Aguará y Barrancas del Paranacito, localizados en el sector septentrional de la llanura aluvial del Paraná medio en su margen santafesina. El objetivo es examinar la relación entre las poblaciones humanas que habitaron dichos espacios y este roedor de gran tamaño, durante el Holoceno tardío. A pesar de su amplia disponibilidad y distribución, su representación en los sitios arqueológicos vinculados a los humedales del río Paraná es escasa y, particularmente en el tramo medio, los sitios aquí considerados se encuentran entre los que tienen una mayor frecuencia. Para esta revisión, se estimó la abundancia taxonómica y anatómica de este taxón y se realizó un relevamiento de las modificaciones de origen antrópico con el fin de inferir las actividades humanas que estarían involucradas en el procesamiento de este recurso. Además, se registró macroscópicamente la incidencia de perturbaciones post-depositacionales, evaluando la meteorización, la acción de raíces, de roedores y carnívoros, y alteraciones químicas. Asimismo, se utilizaron fuentes documentales, etnográficas y etnohistóricas, como marcos de referencia para la interpretación de la información obtenida. Los resultados muestran que, en los casos aquí analizados, esta especie habría sido aprovechada de manera integral, tanto como recurso alimenticio como para la confección de instrumentos. Este aprovechamiento cobra relevancia en la llanura aluvial del Paraná medio, donde son pocos los sitios en los cuales el carpincho representa un porcentaje del NISP mayor a 1. 


\title{
The use of capybara (Hydrochoerus hydrochaeris) at Cerro Aguará and Barrancas del Paranacito sites (General Obligado Department, Santa Fe province)
}

\begin{abstract}
This paper presents a revision of the archaeofaunal record of capybara (Hydrochoerus hydrochaeris) from Cerro Aguará and Barrancas del Paranacito sites, both located on the northern sector of the middle Paraná floodplain, Santa Fe Province. The aim is to explore the relationships between the people who inhabited these sites and this large rodent during the Late Holocene. Despite its high availability and distribution, the representation of this species in archaeological sites related to the Paraná River wetlands is scarce. The sites analyzed in this paper present one of the higher frequencies in the middle section. For this analysis, the taxonomical and anatomical abundance of this species were calculated, and anthropic modifications were examined in order to infer the human activities involved in the processing of this resource. Also, the incidence of taphonomic disturbances was macroscopically recorded, observing weathering, root, rodents, and carnivores marks, as well as chemical alterations. Documentary, ethnographical, and ethnohistorical sources were also used, as a reference frame for interpreting the information. Results indicate that, in the cases analyzed here, this species became relevant as evidenced by its integral exploitation as a food resource and raw material for artifact manufacture. This exploitation of the specie stands out in the middle Parana River floodplain, where its representation surpasses $1 \%$ of the NISP only in few sites.
\end{abstract}

KEYWORDS: Rodents; Middle Paraná; Hunter-gatherers; Late Holocene.

\section{Introducción}

El carpincho (Hydrochoerus hydrochaeris) es un roedor sudamericano de gran tamaño, adaptado a la vida acuática, cuya presencia puede constatarse en los humedales y delta del río Paraná. Sus hábitos gregarios hacen que sea una presa de alto rendimiento económico (un individuo puede aportar hasta $10 \mathrm{~kg}$ de carne, además de grasa y cuero) (Corriale, 2010; Felix et al., 2014; Quintana, 1996; Quiroga Tapias y Garcia Niño, 2014). Distintas fuentes documentales dan cuenta de su amplio aprovechamiento, como las crónicas de Florian Paucke (2010 [1749-1767]), en poblaciones Mocovíes del norte de Santa Fe, y los trabajos etnográficos recientes de Pastor Arenas (2003), en comunidades Wichi y Qom de la provincia de Formosa. A pesar de esto, las investigaciones zooarqueológicas en la llanura aluvial del Paraná medio han evidenciado que, si bien existe una buena representación e incluso un predominio de especies adaptadas a las condiciones del humedal, se da una baja frecuencia de este recurso en los conjuntos (Barboza, 2014, 2016; Barboza y Martín, 2014; Bonomo, Colobig, Passegi, Zucol y Brea, 2010; Cornero, Solomita y Curetti, 2007; Martín, 2015; Ottalagano, 2016, 2019; Ottalagano, Darigo, Pereyra, Brancatelli y lanelli, 2015; Pérez Jimeno, 1996, 2007; Píccoli, Martín y Barboza, 2017; Santiago 2002; Santini, 2009; Sartori, 2013; Sartori y Pérez Jimeno, 2012; Schmitz, Ceruti, González y Rizzo, 1972). Considerando lo expuesto, se realizó una revisión del conjunto faunístico correspondiente a carpincho (Hydrochoerus hydrochaeris) proveniente de los sitios Cerro Aguará (CA) y Barrancas del Paranacito (BP), con el fin de explorar la relación de los grupos humanos que habitaron el sector septentrional de la llanura aluvial del Paraná medio, particularmente en su margen santafesina, con este roedor. 
En el caso de CA, los estudios previos permitieron identificar 355 especímenes de esta especie, de los cuales 251 , que correspondían al material procedente de estratigrafía, fueron analizados en detalle, contando un MNE de 51 y un MNI de 7 (Pérez Jimeno, 2007; Santiago, 2002). Los autores señalaron un predominio de unidades anatómicas de bajo rendimiento económico, principalmente correspondientes al cráneo y miembros anteriores y, entre las evidencias de procesamiento antrópico, se reconocieron marcas de corte en mandíbula, escápula, costilla, cúbito, húmero y metapodios; de quemado en costillas, escápula y falanges; y de pulido en bisel en un fémur.

Por otra parte, en BP, Pérez Jimeno $(1996,2007)$ analizó parte del material faunístico, contabilizando un total de 79 especímenes de carpincho, entre los que identificó hemimandíbulas, piezas dentarias, húmeros, fémures, calcáneos y falanges sin evidencias de procesamiento antrópico. No fueron realizados en este sitio cómputos de elementos e individuos.

La presente revisión constituye una profundización del análisis del registro óseo de Hydrochoerus hydrochaeris respecto de los trabajos precedentes mediante la incorporación del material procedente de zaranda, en CA, y de tres cuadrículas no analizadas previamente, en BP. De este modo, la ampliación de la información disponible permitirá un mejor conocimiento del rol de esta especie para las poblaciones de la región, enriqueciendo la base sobre la cual poder realizar comparaciones a escala regional.

\section{Marco ambiental}

Los sitios bajo estudio se localizan al norte de la provincia de Santa Fe, más específicamente en la Llanura Aluvial del Paraná medio. En este tramo, el cauce principal del río Paraná está compuesto por una sucesión de ensanchamientos, caracterizados por dos o más brazos, con erosión lateral y actividad de sedimentación que forman islas inestables. Estos segmentos limitan con otros estrechamientos breves y bien definidos, en los cuales el río forma un solo canal. De esta dinámica resulta el diseño anastomosado del cauce, el cual, además, presenta un talweg meandriforme (Cordiviola, Giraudo, Lajmanovich, Beltzer y Sottini, 2001).

Este cauce da forma a una llanura compleja que se extiende de norte a sur unos $600 \mathrm{~km}$, desde la confluencia de los ríos Paraná y Paraguay hasta el inicio del delta, cuyo ancho oscila entre los 10 y 25 kilómetros, y que está conformada por diferentes unidades geomorfológicas (barras, meandros, planicies de drenaje imbricado y deltas internos), cada una con sus implicancias ecológicas (Iriondo, Paggi y Parma, 2007). En ella se distinguen un plano de inundación que queda sumergido anualmente al subir el agua, terrazas sumergidas durante las crecientes extraordinarias (cada 10 años aproximadamente, producidas por la coincidencia de las crecientes de colectores y afluentes), y una terraza alta que presenta restos y espiras de meandros y paleoalbardones, controlada principalmente por la crecida de los afluentes. Esta dinámica favorece la formación una gran variedad de biotopos muy complejos espacial y temporalmente, caracterizados por el desarrollo de numerosos hábitats terrestres, acuáticos (lóticos y lénticos) y de interfase acuático-terrestres asociados (Cordiviola et al., 2001).

Ecológicamente esta región ha sido caracterizada como "deltas e islas del Paraná" (Burkart, Bárbaro, Sánchez y Gómez, 1999, p. 26), donde la existencia de grandes volúmenes de agua permanentes genera una reducción de la amplitud térmica, diaria y estacional, permitiendo la distribución de especies y comunidades subtropicales hasta latitudes templadas. La vegetación está compuesta por bosques y arbustales sobre los albardones, pajonales y pastizales en el centro de las islas, comunidades hidrófilas y acuáticas sobre la ribera de los cursos de agua y en las lagunas isleñas. La influencia 
del corredor biogeográfico antes mencionado, la variedad de ambientes y la presencia de refugios naturales determinan la existencia de una fauna considerablemente rica, incluyendo reptiles, de hábitos acuáticos y anfibios (tortugas -Phrynops hilarii, Mesoclemmys vanderhaegei, Acanthochelys pallidipectoris, Acanthochelys spixii $y$ Trachemys dorbigni-, yacarés -Caiman latirostris y Caiman yacare-e iguana overa Tupinambis merianae), una ictiofauna muy diversa (Salminus maxillosus, género Pimelodus, Pseudoplatystoma coruscans, Pseudoplatystoma fasciatum, Paulicea lutkeni y Prochilodus lineatus, entre otros), gran cantidad de aves de hábitos acuáticos (Ardea cocoi, Gallinula chloropus, Anas platalea y Jabiru mycteria) y migratorios (por ejemplo, géneros Calidris y Tringa), y mamíferos terrestres (Lutreolina crassicaudata, Didelphis albiventris, Mazama gouazoubira, Oncifelis geoffroyi, Chrysocyon brachyurus, Dasypus novemcinctus, Priodontes maximus y Cavia aperea, entre otros) y con adaptaciones acuáticas (Lontra longicaudis, Blastocerus dichotomus, Myocastor coypus e Hydrochoerus hydrochaeris) (Burkart et al., 1999; Cordiviola et al., 2001).

\section{Etología del carpincho}

Hydrochoerus hydrochaeris (Linnaeus, 1766), comúnmente conocido en Argentina como carpincho, está adaptado a la vida acuática, con capacidad para nadar y bucear, pudiendo permanecer sumergido hasta 10 minutos (Corriale, 2010). Es un animal gregario por lo que suele formar grupos cuya estabilidad varía estacionalmente, ya que durante el período seco la cohesión se reduce y el tamaño del grupo es muy aleatorio, mientras que en la temporada de lluvias se congregan en grupos familiares más estables. También es factible encontrar individuos aislados en determinados tipos de hábitats como los bosques en galería o con alta presión de caza (González Jiménez, 1995; Quintana, 1996).

Los individuos adultos de esta especie pueden medir de 1 a $1,5 \mathrm{~m}$ de longitud y 0,5 a $0,65 \mathrm{~m}$ de altura a la cruz, y pesar más de $50 \mathrm{~kg}$. Sin embargo, existe una clina latitudinal, ya que su peso y talla se incrementan hacia el sur, llegando en Argentina y el sur de Brasil a sobrepasar los $80 \mathrm{~kg}$ (González Jiménez, 1995). Estas características lo definen como el roedor más grande del mundo e integra el reducido grupo de los grandes herbívoros sudamericanos (constituyen sólo el $3 \%$ del total de especies de mamíferos nativos de esta región). En relación a sus hábitos reproductivos, no tiene una época definida de celo, por lo que puede reproducirse durante todo el año (Quintana, 1996). En general, tienen una camada (entre una y ocho crías) al año, aunque en condiciones favorables pueden reproducirse dos veces (Corriale, 2010).

Respecto a su potencial uso como recurso, de un individuo de aproximadamente 36 $\mathrm{kg}$ pueden obtenerse unos $14,5 \mathrm{~kg}$ de carne, de los cuales un $29,3 \%$ corresponde al miembro posterior, un $15,6 \%$ al miembro anterior y el $11,8 \%$ al lomo (Quiroga Tapias y Garcia Niño, 2014). Evaluaciones sobre la composición de la carne indican un $20,58 \%$ de proteínas y $1,46 \%$ de lípidos, siendo el pecho y los cuartos traseros los que contienen valores más altos de estos últimos (1,8\%) (Felix et al., 2014).

\section{Los sitios Cerro Aguará y Barrancas del Paranacito}

Como se dijo anteriormente, ambos sitios se localizan en el sector septentrional de la llanura aluvial del Paraná medio. En consecuencia, se encuentran sujetos al régimen pulsional de este gran río (Figura 1).

El sitio CA se encuentra emplazado en un albardón sobre la margen derecha del arroyo Chará y fue excavado por la Dra. Pérez Jimeno entre 1998 y 2000. Las intervenciones 


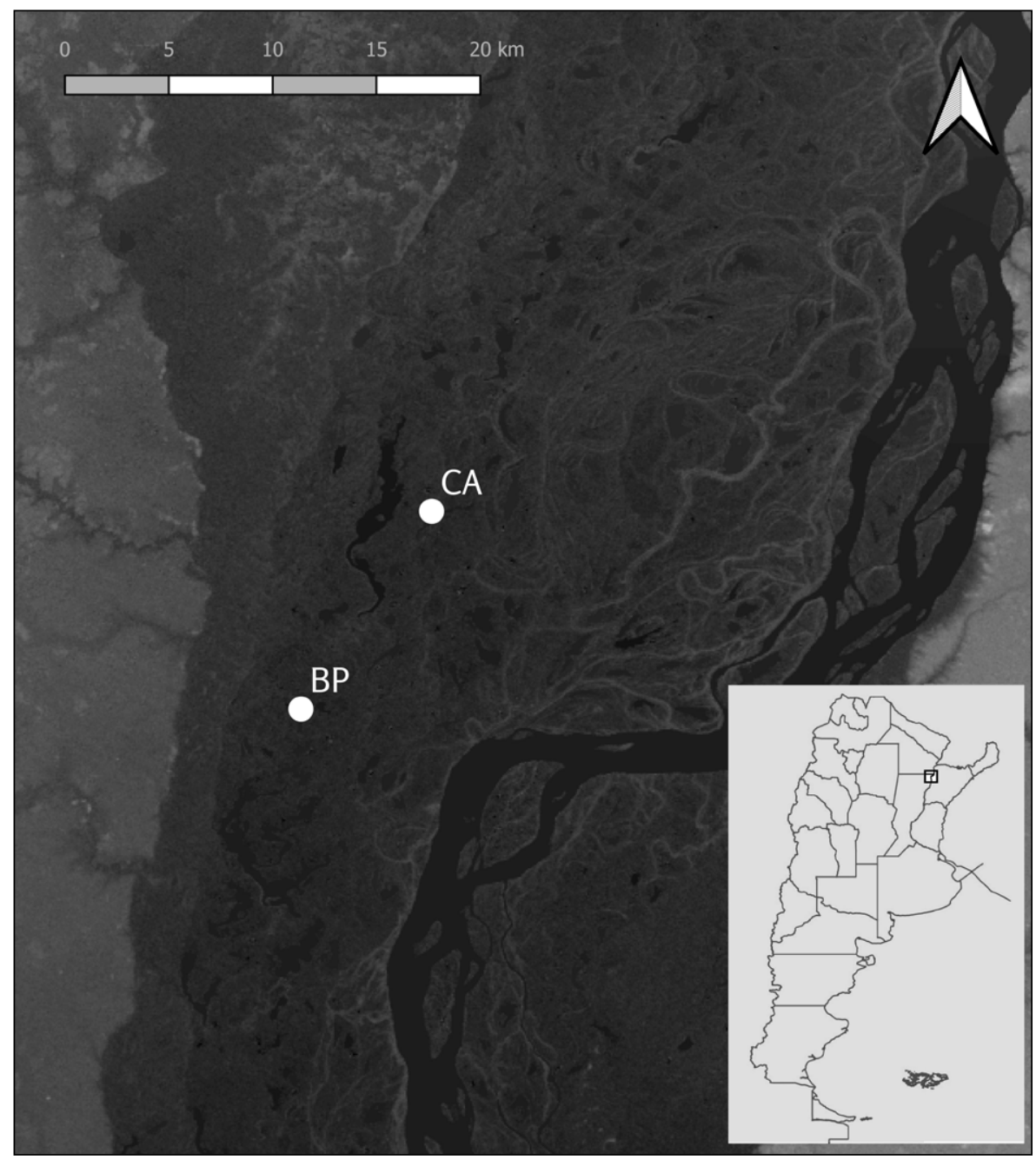

Figura 1. Localización de los sitios Cerro Aguará y Barrancas del Paranacito.

constaron de la realización de una cuadrícula (A) de $3 \times 2 \mathrm{~m}$, la cual fue ampliada en un sector de $1 \times 2 \mathrm{~m}$. En total se excavaron $8 \mathrm{~m} 2$ de superficie hasta $0,71 \mathrm{~m}$ de profundidad, sumando un volumen total de $5,68 \mathrm{~m} 3$. Se procedió por niveles artificiales de 0,05 $\mathrm{m}$ y se tamizó con agua el sedimento en zarandas con malla de 1 $\mathrm{mm}$. Se ha recuperado un cuantioso material arqueológico, que incluye fragmentos de cerámica, instrumentos óseos, valvas de moluscos de agua dulce, algunas cuentas manufacturadas en este material y restos óseos faunísticos de diversos vertebrados. El análisis zooarqueológico ha indicado un predominio de recursos de baja jerarquía, pero que dadas su predictibilidad, abundancia y fácil captura, aportarían altas tasas de retorno, como peces (Musali y Pérez Jimeno, 2016; Pérez Jimeno, 2007, 2009), moluscos (Pérez Jimeno, 2007, 2008) y Cavia aperea (Pérez Jimeno, 2007; Santiago, 2002). También se habrían explotado mamíferos medianos, como Myocastor coypus (Pérez Jimeno, 2007; Santiago, 2002), y grandes, como cérvidos -Blastocerus dichotomus, Ozotoceros bezoarticus - (Mucciolo y Pérez Jimeno, 2015; Pérez Jimeno, 2007) e Hydrochoerus hydrochaeris (Pérez Jimeno, 2007; Santiago, 2002) además de aves, en menor medida (Pérez Jimeno, 2007; Pérez Jimeno y Servin, 2017) (Tabla 1). Este sitio posee dos dataciones, realizadas sobre restos óseos de Blastocerus dichotomus, que arrojaron fechas (895 60 - $530 \pm 70$ años AP - LP 139 y LP 1431, respectivamente) que indican que ha sido ocupado recurrentemente a lo largo del Holoceno tardío. 
Por su parte, BP se sitúa en un albardón sobre la margen izquierda de río Paraná Miní. Este sitio fue excavado por el equipo del Dr. Ciro R. Lafón durante los años 1969 y 1971 y consta de dos sectores separados entre sí por aproximadamente 100 metros. En el sector 1 se excavaron 14 cuadrículas sumando unos $126 \mathrm{~m} 2$; en el sector 2, cuatro cuadrículas, con un total excavado de $40 \mathrm{~m} 2$. En ellos se alcanzó una profundidad de 0,60 m, lo cual resultó en un volumen de 99,6 m3. Los materiales arqueológicos se encontraban estratigráficamente en tres capas de valvas de moluscos separadas por franjas delgadas de sedimento arqueológicamente estériles. Los sedimentos fueron cernidos en seco en zarandas con malla de $5 \mathrm{~mm}$. Se recuperaron abundante material cerámico y faunístico (aunque con menor densidad que en CA), instrumentos óseos y, además, se hallaron múltiples enterratorios humanos. Si bien este sitio no cuenta con dataciones absolutas, dada la presencia de una fauna adaptada a un ambiente cálido y húmedo, ha sido situado cronológicamente en el Holoceno tardío (Pérez Jimeno, 1996, 2007). En cuanto al material faunístico, hay un predominio de mamíferos, principalmente cérvidos y Cavia aperea, seguido por peces y, en menor medida, aves y reptiles (Tabla1).

\begin{tabular}{|l|c|c|c|c|c|c|}
\hline \multirow{2}{*}{ Taxa } & \multicolumn{3}{|c|}{ CA } & \multicolumn{3}{|c|}{ BP } \\
\cline { 2 - 7 } & NISP & $\%$ & MA & NISP & $\%$ & MA \\
\hline Peces & 29.185 & 88,11 & $\mathrm{X}$ & 696 & 15,9 & \\
Reptilia & 285 & 0,86 & & 231 & 5,3 & \\
Aves & 370 & 1,12 & $\mathrm{X}$ & 431 & 9,9 & \\
Mammalia indeterminada & 276 & 0,83 & & 1.472 & 33,7 & \\
Carnívora & 2 & 0,01 & & 12 & 0,3 & \\
Cervidae & 15 & 0,05 & & 40 & 0,9 & \\
Blastocerus dichotomus & 273 & 0,82 & $\mathrm{X}$ & 212 & 4,9 & $\mathrm{X}$ \\
Ozotoceros bezoarticus & 64 & 0,19 & $\mathrm{X}$ & 85 & 1,9 & $\mathrm{X}$ \\
Bos taurus & 23 & 0,07 & & 21 & 0,5 & \\
Rodentia & 11 & 0,03 & & 0 & 0 & \\
Hydrochoerus hydrochaeris & 355 & 1,07 & $\mathrm{X}$ & 79 & 1,8 & \\
Myocastor coypus & 202 & 0,61 & $\mathrm{X}$ & 127 & 2,9 & \\
Cavia aperea & 2.050 & 6,19 & $\mathrm{X}$ & 958 & 22,0 & \\
Holochilus chacarius & 12 & 0,04 & & 0 & 0 & \\
\hline Total & 33.123 & 100 & & 4.364 & 100 & \\
\hline
\end{tabular}

Tabla 1. Composición taxonómica de vertebrados de los sitios CA y BP (NISP y NISP\%) y presencia de modificaciones antrópicas (MA), incluyendo marcas de procesamiento y alteración térmica, de acuerdo a la información disponible en bibliografía (Mucciolo y Pérez Jimeno, 2015; Pérez Jimeno, 2007; Pérez Jimeno y Servin, 2017).

\section{Materiales y métodos}

Las muestras analizadas en este trabajo fueron ampliadas respecto de las estudiadas previamente (Pérez Jimeno, 1996, 2007; Santiago, 2002). Por un lado, en CA se habían calculado medidas de abundancia taxonómica y anatómica del registro faunístico correspondiente a carpincho procedente de estratigrafía (251 especímenes), y se habían registrado en este conjunto, evidencias de procesamiento antrópico y alteraciones óseas post-depositacionales (Pérez Jimeno, 2007; Santiago, 2002). Sin embargo, del material óseo recuperado en zaranda sólo se realizó un conteo de especímenes asignados a Hydrochoerus hydrochaeris (104 especímenes) (Acosta, Escudero, Feuillet Terzaghi, Loponte y Pérez Jimeno, 2009; Pérez Jimeno, 2007). Para el presente trabajo 
se analizaron estos últimos y se realizó una revisión del material de estratigrafía que habia sido estudiado previamente, al cual se incluyeron especímenes de carpincho que anteriormente no habían podido identificarse a nivel específico y habían sido clasificados como Mammalia indeterminada. Por otra parte, en BP los estudios precedentes, realizados sobre el material faunístico correspondiente a las cuadrículas H0, H1, G0, G1, J1 y K1, del sector 1, y 1, 2, 3 y 4, del sector 2 (Pérez Jimeno, 1996, 2007), incorporaron el conteo de especímenes asignados a Hydrochoerus hydrochaeris y a cada unidad anatómica. Para el análisis presentado en este artículo, se examinó nuevamente el conjunto óseo de este roedor, al cual se adicionó el recuperado de las cuadrículas F0, F2 y G2 y especímenes previamente clasificados como mamíferos indeterminados. Los materiales correspondientes a las cuadrículas $\mathrm{F} 1, \mathrm{H} 2,11,12$ y J2 no pudieron ser localizados, por lo cual no fueron considerados para este trabajo (Figura 2).

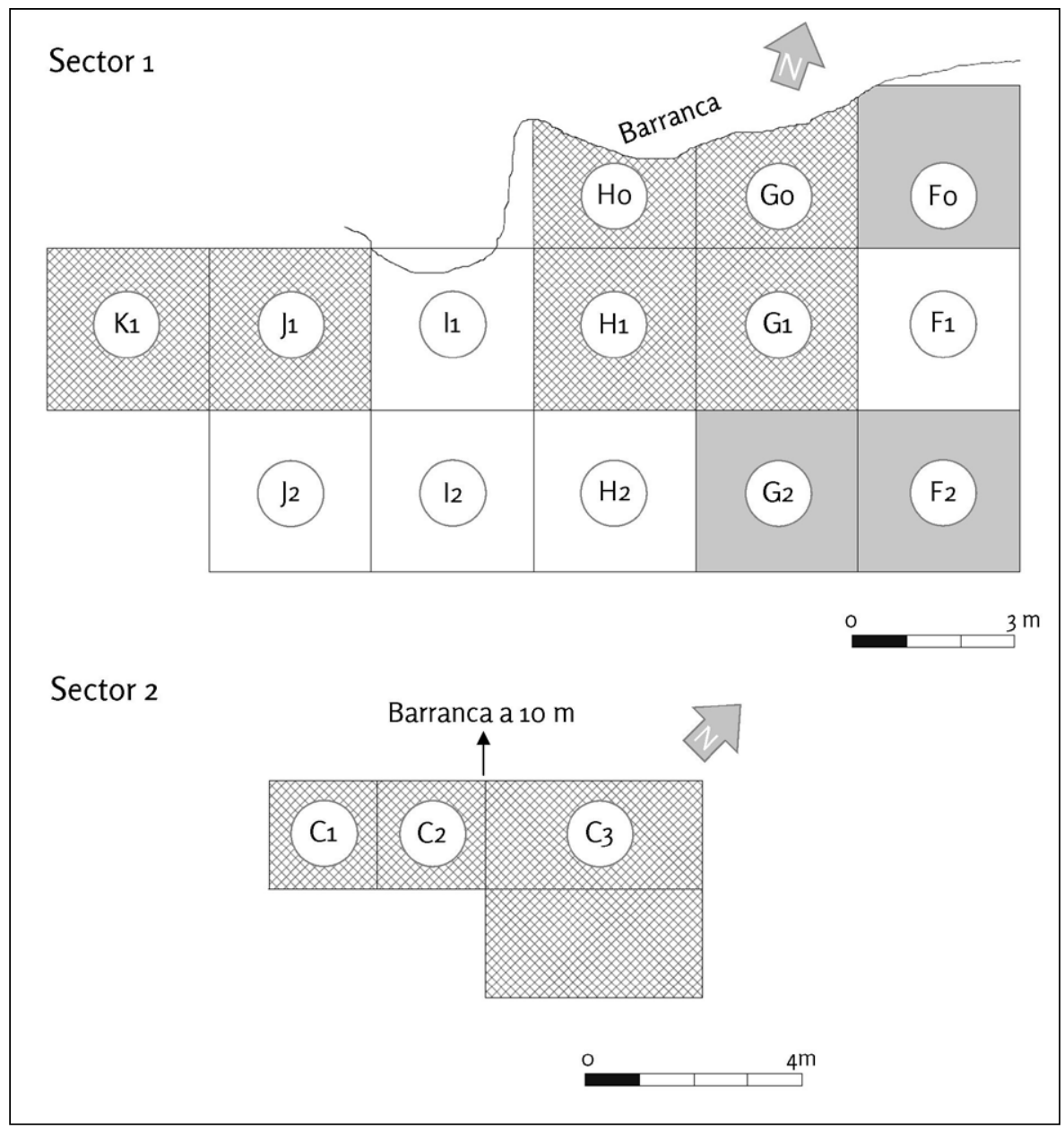

Figura 2. Planta de ambos sectores del sitio BP (adaptado de Pérez Jimeno, 2007, figuras 5.57 y 5.58). Con relleno en rejilla las cuadrículas que habían sido analizadas en trabajos anteriores, en gris las incorporadas en este análisis. No pudo ser rastreada en las libretas de campo la localización de la cuadrícula C4.

Metodológicamente, se realizó la estimación de abundancia taxonómica y anatómica (Grayson, 1984; Lyman, 2008; Mengoni Goñalons, 1999). Se cuantificó el número de especímenes óseos (NISP) para cada unidad anatómica, aunque se descartaron las piezas dentarias debido a su fácil fragmentación, incluso durante su manipulación en laboratorio (Sartori, 2013). Luego se calculó el número mínimo de elementos (MNE) mediante el cómputo de la porción de hueso o zona diagnóstica más frecuente en cada unidad anatómica (Binford, 1984; Mengoni Goñalons, 1999, 2010). En huesos largos 
se definieron tres porciones (proximal, diáfisis y distal) y para los demás se utilizaron zonas diagnósticas de acuerdo con la descripción de Bode y colaboradores (Bode, Cao, Resoagli, Fernández y Llano Laiseca, 2014; Bode, Fernández, Cao y Resoagli, 2013). Sobre la base de MNE obtenido se calculó el número mínimo de individuos (MNI), diferenciando lateralidad en los huesos pares (Mengoni Goñalons, 1999, 2010). Luego se computó el número mínimo de unidades anatómicas (MAU). Ulteriormente, se calculó el índice de fragmentación, dividiendo el MNE de cada unidad anatómica por su valor de NISP (Mengoni Goñalons, 1999, 2010).

Por otra parte, se evaluó macroscópicamente la incidencia de perturbaciones postdepositacionales en la muestra, tales como meteorización (según los estadios establecidos por Behrensmeyer, 1978), la acción de roedores, carnívoros y raíces, y las alteraciones químicas (Lyman, 1994; Mengoni Goñalons, 2010). Además, se analizaron macroscópicamente y bajo lupa de $5 X$, las huellas antrópicas, reconociendo ubicación, tipo y orientación. Las evidencias de alteraciones térmicas, se clasificaron de acuerdo con la coloración y textura, registrando si ésta es uniforme o no (Frank, 2011; Stiner y Kuhn, 1995). Las fracturas de origen antrópico fueron consignadas por las unidades anatómicas que las presentan, la forma y los atributos asociados (Binford, 1981; Lyman, 1994; Mengoni Goñalons, 2010).

Para la interpretación de los datos obtenidos, se emplearon también fuentes documentales en las que se hiciera referencia a la relación entre grupos humanos cuyo tipo de subsistencia podría ser comparable con la de quienes habitaron estos sitios, y el carpincho. Si bien estas fuentes fueron producidas en contextos histórico-sociales diferentes, ofrecen marcos actualísticos, basados en regularidades conductuales, para la generación de interpretaciones (Sartori, 2015).

\section{Una aproximación al aprovechamiento del carpincho por parte de poblaciones cazadoras-recolectoras desde fuentes etnohistóricas y etnográficas}

Las fuentes documentales incluidas fueron, por un lado, las crónicas del misionero jesuita Florián Paucke (2010 [1749-1767], sobre su estadía con poblaciones Mocovíes entre 1749 y 1767 en la reducción de San Javier (Santa Fe), en un entorno ambiental similar al de los sitios aquí analizados. Por otro lado, fueron exploradas las investigaciones de Pastor Arenas (2003) sobre la alimentación en comunidades Wichi y Qom, en el oeste de la provincia de Formosa, entre 1983 y 2001. A pesar de las diferencias ambientales, se detallan particularidades de la valoración y procesamiento del carpincho.

En primer lugar, Paucke relata acerca de la disponibilidad, el aprovechamiento y la preferencia por esta especie entre los pobladores de la reducción. También lo señala como un recurso importante en momentos de crecidas del río cuando el territorio se reducía. Al respecto señala que las capturas serían de más de un individuo:

Los caballos estaban liados de pura carne de carpinchos que apenas podían transportar. A propósito conté cuántos habrían matado entre grandes, medianos y chicos había cuarenta y tres piezas de ellos. Los puercos más grandes eran en realidad tan grandes y aún más grandes que un cerdo manso mediano (Paucke, 2010 [1749-1767], p. 304).

Asimismo, describe las estrategias de caza utilizando lanzas de madera de una morfología definida, flechas o mazas. Si bien señala la facilidad con la que realizaban esta actividad, ésta requería una técnica particular: 
Tampoco se precisa más sino que ellos vean sólo la cabeza del carpincho nadante: entonces calculan la medida que en poco errarán el cuerpo. Una vez que el dardo está clavado en el animal, saltan entonces al río, nadan tras el carpincho, asen el palo cuya parte sobresale del agua e indica hacia donde nada el carpincho herido, sacan éste para afuera a la orilla y lo matan con sus mazas. (Paucke, 2010 [1749-1767], p. 304).

Sobre su procesamiento indica que sólo las entrañas eran abandonadas en el lugar de cacería y que los individuos eran despostados de acuerdo con el tamaño, cocinados luego con cueros mediante hervido (Paucke, 2010 [1749-1767]). Además, insinúa una jerarquización en el aprovechamiento de las unidades anatómicas, dado que priorizarían aquellas con mayor contenido de grasa (estómago y cuello). Respecto al cuero del animal, refiere que era utilizado en ocasiones para la confección de sacos, una vez consumida la carne adherida al mismo. Por último, menciona que, si bien esta especie era cazada y consumida, esto no excluye que a veces fuera ingresada viva al ámbito doméstico (i.e. como mascota).

Por su parte, Arenas (2003) señala que, entre las comunidades Wichi y Qom del oeste de Formosa, antiguamente se los cazaba mediante flechas, fijas, palos aguzados o garrotes. Los encontraban agrupados en humedales o en el monte, donde eran perseguidos por los perros hasta el agotamiento. Asimismo, refiere que la estación preferida para su caza era entre agosto y noviembre cuando los bañados, cauces y pantanos están secos, y observa que los animales eran transportados completos a los espacios domésticos donde, exceptuando algunas partes descartadas (ciertas vísceras y patas), era consumido integralmente, cocinado mediante el asado o hervido. Destaca el consumo de la cabeza "Esta porción es preferida cocida; de esta manera se ocupa también el seso, que les resulta apetecible" (Arenas, 2003, p. 437). La carne solía ser almacenada, luego de ser asada o desecada, para consumo diferido, y el contenido de grasa, que además de alimento tenía un uso medicinal, era muy valorado. Por último, fue referido el uso del cuero para el guardado de harinas o panes de algarrobo.

De acuerdo a lo planteado en las fuentes documentales relevadas, el carpincho habría sido explotado por poblaciones originarias de la región tanto en momentos históricos como en la actualidad. Su valor como recurso alimenticio radicaría en el aporte de carne, vísceras y grasa. También sería aprovechado el cuero, aunque no se menciona, como sucede con otras especies, el cuereo como una etapa previa a la cocción. Por último, estos usos no excluyen otro tipo de valoraciones no económicas como la mascotización (Paucke, 2010 [1749-1767]).

\section{Resultados}

\section{Abundancia taxonómica y perfiles anatómicos}

En CA, el total de especímenes identificados como Hydrochoerus hydrochaeris fue de 378. Dado que la identificación y conteo de especímenes procedentes de zaranda ya había sido realizado en trabajos previos (Acosta et al., 2009: Pérez Jimeno, 2007), el incremento corresponde a la reclasificación de huesos que habían sido asignados a Mammalia indeterminada. Asimismo, se computaron 268 elementos. En este sitio las unidades anatómicas mejor representadas fueron escápula, radio, rótula, calcáneo y astrágalo (MAU 4 a 6), seguido por los demás huesos largos del estilopodio y zeugopodio (excepto por la fíbula, que está ausente), carpianos, tarsianos, metapodios, cráneo y hemimandíbula (MAU 2 a 3,9). Los elementos del esqueleto axial postcraneal, pelvis y falanges son los que presentan valores de MAU más bajos (Tabla 2, Figura 3 ). 
En BP se determinaron 261 especímenes correspondientes a carpincho y se calcularon 163 elementos. El incremento $(n=182)$ resulta del agregado de las tres cuadrículas $(n$ = 14) y de la identificación de especímenes que estaban previamente clasificados a nivel de clase Mammalia $(n=168)$. Aquí las unidades anatómicas mejor representadas corresponden al zeugopodio anterior (MAU 4 y 4,5), seguidas por los demás elementos de los quiridios, excepto por algunos huesos cortos, cráneo y hemimandíbula (MAU 2 a 3,9). El esqueleto axial postcraneal (únicamente representado por vértebras y una costilla), las cinturas, rótulas, carpianos, tarsianos y falanges presentan valores de MAU menores a 2 (Tabla 2). Cabe señalar que algunas de las unidades anatómicas de este último poseen bajo valor diagnóstico para su determinación taxonómica cuando no se encuentran completas, lo cual dificulta su identificación respecto de otros taxa de tamaño mediano, lo cual puede contribuir a su baja representación (Tabla 2, Figura 3).

Se estableció un MNI de siete para cada sitio, a partir de los radios - que es la unidad anatómica mejor representada en ambos-. En el caso de CA este valor se mantiene respecto a estudios anteriores, pero en BP no había sido determinado.

En ambos sitios las unidades anatómicas más fragmentadas fueron cráneo y hemimandíbulas (índices de fragmentación entre 0,1 y 0,3). Los valores de fragmentación en vértebras $(C A=0,82 ; B P=0,71)$ se vinculan principalmente a la separación de las caras articulares y las costillas; si bien presentaron valores medios $(0,49)$ en CA y nulos en $\mathrm{BP}$, en todos los casos se encontraron fracturadas. En esternebras y sacro, que sólo se encontraron en CA, huesos cortos de los quiridios, cintura escapular, este índice fue

\begin{tabular}{|c|c|c|c|c|c|c|c|c|c|c|}
\hline \multirow{2}{*}{ Unidades anatómicas } & \multicolumn{5}{|c|}{ CA } & \multicolumn{5}{|c|}{ BP } \\
\hline & NISP & NISP\% & MNE & MAU & $\begin{array}{l}\text { MNE/ } \\
\text { NISP }\end{array}$ & NISP & NISP\% & MNE & MAU & $\begin{array}{l}\text { MNE/ } \\
\text { NISP }\end{array}$ \\
\hline Cráneo & 28 & 7,41 & 3 & 3 & 0,11 & 21 & 8,05 & 2 & 2 & 0,10 \\
\hline Hemimandíbula & 13 & 3,44 & 4 & 2 & 0,31 & 28 & 10,73 & 4 & 2 & 0,14 \\
\hline Vértebras & 38 & 10,05 & 31 & 0,9 & 0,82 & 14 & 5,36 & 10 & 0,3 & 0,71 \\
\hline Costillas & 43 & 11,38 & 21 & 0,6 & 0,49 & 1 & 0,38 & 1 & 0 & 1,00 \\
\hline Esternebras & 6 & 1,59 & 6 & 0,2 & 1,00 & 0 & 0 & 0 & - & - \\
\hline Sacro & 3 & 0,79 & 3 & 3 & 1,00 & 0 & 0 & 0 & - & - \\
\hline Escápula & 10 & 2,65 & 10 & 5 & 1,00 & 3 & 1,15 & 3 & 1,5 & 1,00 \\
\hline Húmero & 11 & 2,91 & 5 & 2,5 & 0,45 & 10 & 3,83 & 6 & 3 & 0,60 \\
\hline Cúbito & 10 & 2,65 & 6 & 3 & 0,60 & 9 & 3,45 & 8 & 4 & 0,89 \\
\hline Radio & 19 & 5,03 & 10 & 5 & 0,53 & 15 & 5,75 & 9 & 4,5 & 0,60 \\
\hline Pelvis & 5 & 1,32 & 3 & 1,5 & 0,60 & 2 & 0,77 & 2 & 1 & 1,00 \\
\hline Fémur & 12 & 3,17 & 6 & 3 & 0,50 & 22 & 8,43 & 7 & 3,5 & 0,32 \\
\hline Rótula & 13 & 3,44 & 12 & 6 & 0,92 & 3 & 1,15 & 3 & 1,5 & 1,00 \\
\hline Tibia & 8 & 2,12 & 4 & 2 & 0,50 & 11 & 4,21 & 6 & 3 & 0,55 \\
\hline Calcáneo & 9 & 2,38 & 9 & 4,5 & 1,00 & 4 & 1,53 & 4 & 2 & 1,00 \\
\hline Astrágalo & 9 & 2,38 & 9 & 4,5 & 1,00 & 6 & 2,3 & 6 & 3 & 1,00 \\
\hline Carpianos / tarsianos & 28 & 7,41 & 28 & 2,3 & 1,00 & 9 & 3,45 & 9 & 0,8 & 1,00 \\
\hline Metapodios & 66 & 17,46 & 52 & 3,3 & 0,79 & 60 & 22,99 & 44 & 2,8 & 0,73 \\
\hline Falanges & 47 & 12,43 & 46 & 1 & 0,98 & 43 & 16,48 & 39 & 0,8 & 0,91 \\
\hline Total & 378 & 100 & 268 & & & 261 & 100 & 163 & & \\
\hline
\end{tabular}


mayor a 0,9. Respecto a la cintura pélvica se observó diferencias entre ambos sitios, con 0,6 en CA y uno en BP. La mayor parte de los huesos largos del esqueleto apendicular tienen una fragmentación moderada (entre 0,45 y 0,8$)$, excepto por el cúbito $(0,88)$ y el fémur $(0,31)$ en BP (Tabla 2).

\section{Alteraciones naturales post-depositacionales}

La meteorización afectó a $67,46 \%$ de los especímenes en CA $(n=255)$, y a 39,85\% en $B P(n=104)$. Entre éstos predominaron los estadios $1(n=150$, en el primero; $n$ $=58$, en el segundo) y $2(n=69 ; n=32$, respectivamente). Pocos especímenes $(n=$ 33 y 13 , respectivamente) fueron incluidos en el estadio 3 , y solo tres de CA y uno de BP en el 4.

Además, se observó la incidencia de tinción por óxido de manganeso en 89 especímenes de CA (23,54\%), y en 110 de BP (42,14\%), aunque en la mayoría de los casos sólo son manchas parciales, encontrándose en porciones del hueso de forma moteada. También se registró la adhesión de concreciones calcáreas, pero sólo en el caso de CA ( $\mathrm{n}=$ $16 ; 4,23 \%)$.

Por otra parte, se identificaron improntas de raíces en 21 especímenes de CA $(5,5 \%)$ y en 24 de BP (9,19\%). La acción de roedores fue recurrente, observándose marcas en 33 huesos de CA $(8,73 \%)$ y en 14 de BP $(5,36 \%)$. Las huellas de carnívoros sólo se presentaron en 2 especímenes de CA $(0,53 \%)$.

En síntesis, se pudo determinar que, en general, los conjuntos tienen un buen estado de preservación, con escasa meteorización y bioturbación, y moderada acción química. Estas características, semejantes a las observadas en el total del conjunto de vertebrados de estos sitios, sugieren que el enterramiento habría sido relativamente rápido, lo cual es congruente con las características del emplazamiento de los sitios (Musali y Pérez Jimeno, 2016; Pérez Jimeno, 1996, 2007; Santiago, 2002). Asimismo, implican que ambos habrían sido afectados por procesos y agentes postdepositacionales similares, lo cual contribuyó a la comparabilidad de ambos conjuntos.

\section{Modificaciones óseas de origen antrópico}

En las dos colecciones analizadas se registraron especímenes con modificaciones de origen antrópico, correspondiendo 66 a CA (17,46\%) y 37 a BP (14,18\%) (Figura 3, Tabla 3).

En CA se distinguieron marcas de corte transversales en 19 especímenes, las cuales se situaban en mandíbula, maxilar, vértebras cervicales y sacras, en la cara articular distal del húmero, en sectores proximales de cúbito y radio, en la epífisis proximal y tróclea del fémur, rótula y calcáneo. Las oblicuas (4 especímenes) se localizaron en hemimandíbula y en epíisis proximales de cúbito y radio. Se reconocieron longitudinales en diáfisis de fémur, rótula y calcáneo. También se observaron 12 especímenes con cortes de orientación indeterminada, entre ellos el hueso posterior del cráneo, en el acetábulo, en astrágalo, tarsianos (tercero y central) y carpianos (escalfolunatum). En general, las marcas eran poco profundas y aisladas, y sólo se presentaron varios cortes agrupados en un fémur y un radio. Asimismo, se reconoció una marca de raspado en un hueso frontal del cráneo (Figura 4, Tabla 3).

En BP se registraron marcas de corte transversales en 9 especímenes correspondientes a hemimandíbula, costilla, segmento proximal de cúbito, epífisis proximal y distal de 


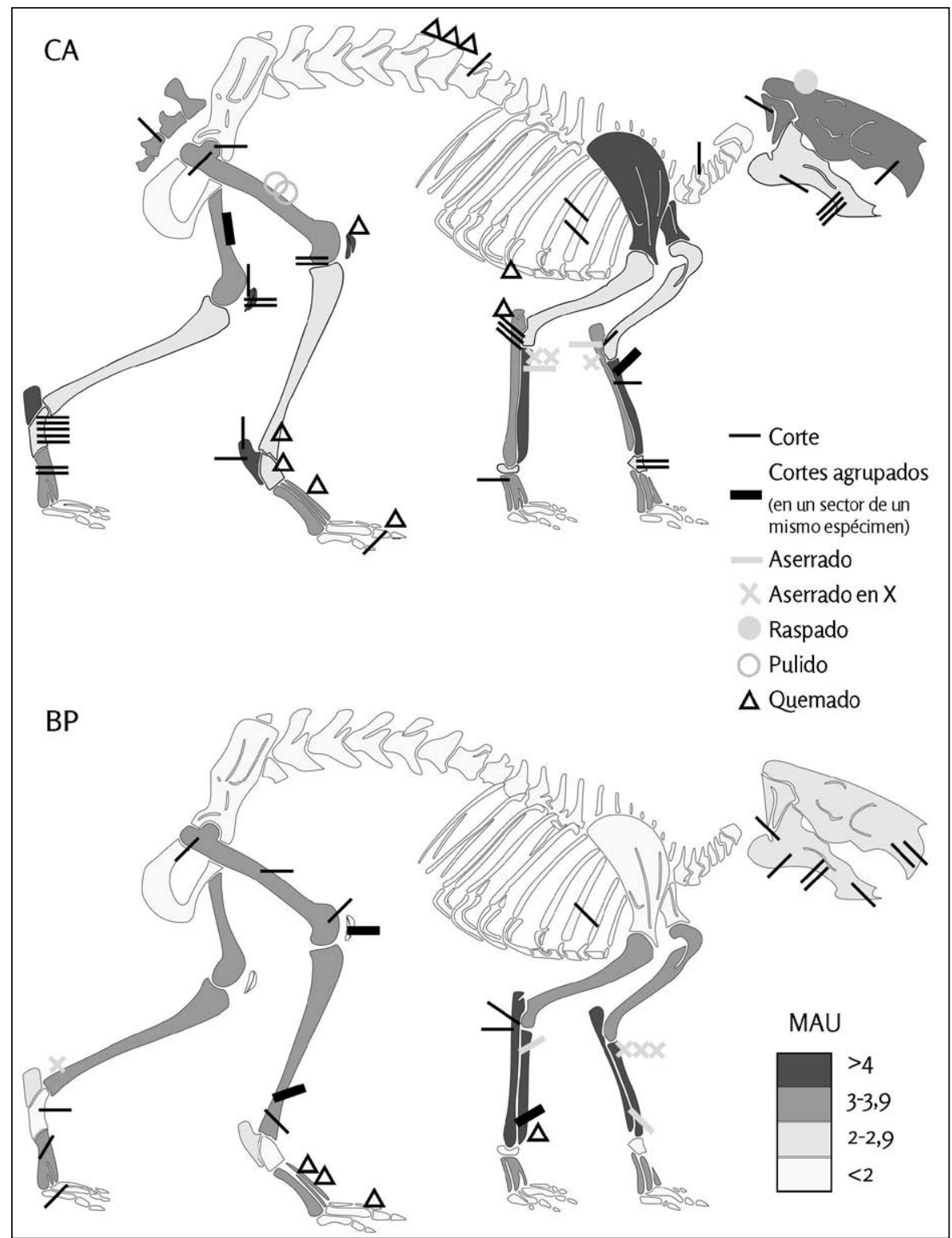

Figura 3. Representación anatómica (MAU) de Hydrochoerus hydrochaeris y modificaciones antrópicas. Cada símbolo representa un espécimen.

fémur, rótula, tibia distal y falange; oblicuas ( 6 especímenes) en fosa muscular de hemimandíbula, cúbito proximal, radio distal, epífisis distales de fémur y tibia, y en un metapodio; longitudinales en un maxilar y en el incisivo de una mandíbula; y de orientación indeterminada en un astrágalo, maxilar y hemimandíbula. Estas eran superficiales y solo una tibia, una rótula y un radio presentaron varias en forma agrupada (Figura 4, Tabla 3).

En CA se observó aserrado en $\mathrm{X}$ en dos epífisis proximales de radio y una de cúbito; esta última también presentaba aserrado transversal. Asimismo, se registró un radio proximal con aserrado perimetral. En BP se distinguieron aserrados en $X$ en radios proximales y una tibia distal. También se reconocieron dos epífisis, una distal y otra proximal, de radio con aserrado oblicuo. Además, dos fémures de CA que conservan la epífisis proximal y la diáfisis, presentan el borde distal pulido (Figura 5). 


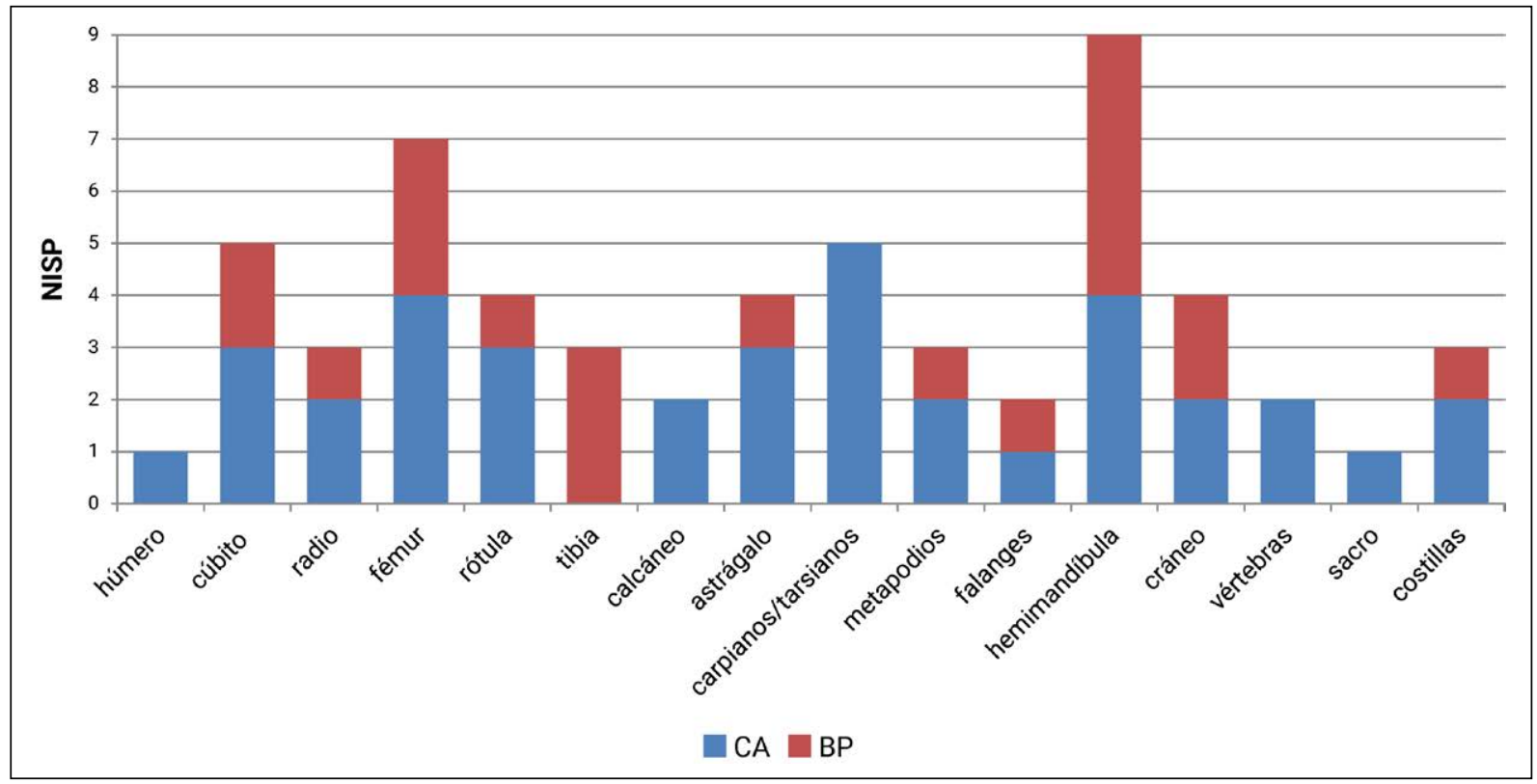

Figura 4. Marcas de corte sobre especímenes de Hydrochoerus hydrochaeris de CA y BP.

\begin{tabular}{|c|c|c|c|c|c|c|c|c|c|c|c|c|}
\hline \multirow{2}{*}{ Unidades anatómicas } & \multicolumn{2}{|c|}{ Corte } & \multicolumn{2}{|c|}{ Raspado } & \multicolumn{2}{|c|}{ Aserrado } & \multicolumn{2}{|c|}{ Pulido } & \multicolumn{2}{|c|}{ Quemado } & \multicolumn{2}{|c|}{ Fracturas } \\
\hline & CA & BP & CA & BP & CA & BP & CA & BP & CA & BP & CA & BP \\
\hline Cráneo & 2 & 2 & 1 & & & & & & & & & \\
\hline Hemimandíbula & 4 & 5 & & & & & & & & & & \\
\hline Vértebras & 2 & & & & & & & & 3 & & & \\
\hline Costillas & 2 & 1 & & & & & & & & & & \\
\hline Esternebras & & & & & & & & & 1 & & & \\
\hline Sacro & 1 & & & & & & & & & & & \\
\hline Húmero & 1 & & & & & & & & & & & 1 \\
\hline Cúbito & 3 & 2 & & & 1 & & & & 2 & & 1 & \\
\hline Radio & 2 & 1 & & & 3 & 5 & & & & 1 & 4 & 4 \\
\hline Ilíaco & 1 & & & & & & & & & & & \\
\hline Fémur & 4 & 3 & & & & & 2 & & & & 3 & 1 \\
\hline Rótula & 3 & 1 & & & & & & & 1 & & & \\
\hline Tibia & & 2 & & & & 1 & & & 1 & & 1 & 1 \\
\hline Calcáneo & 2 & & & & & & & & & & & \\
\hline Astrágalo & 3 & 1 & & & & & & & & & & \\
\hline Carpianos/tarsianos & 5 & & & & & & & & 1 & & & \\
\hline Metapodios & 2 & 1 & & & & & & & 2 & 2 & & \\
\hline Falanges & 1 & 1 & & & & & & & 1 & 1 & & \\
\hline Total & 38 & 20 & 1 & 0 & 4 & 6 & 2 & 0 & 12 & 4 & 9 & 7 \\
\hline
\end{tabular}

Tabla 3. Modificaciones de origen antrópico sobre especímenes óseos de Hydrochoerus hydrochaeris (sitios CA y BP). 


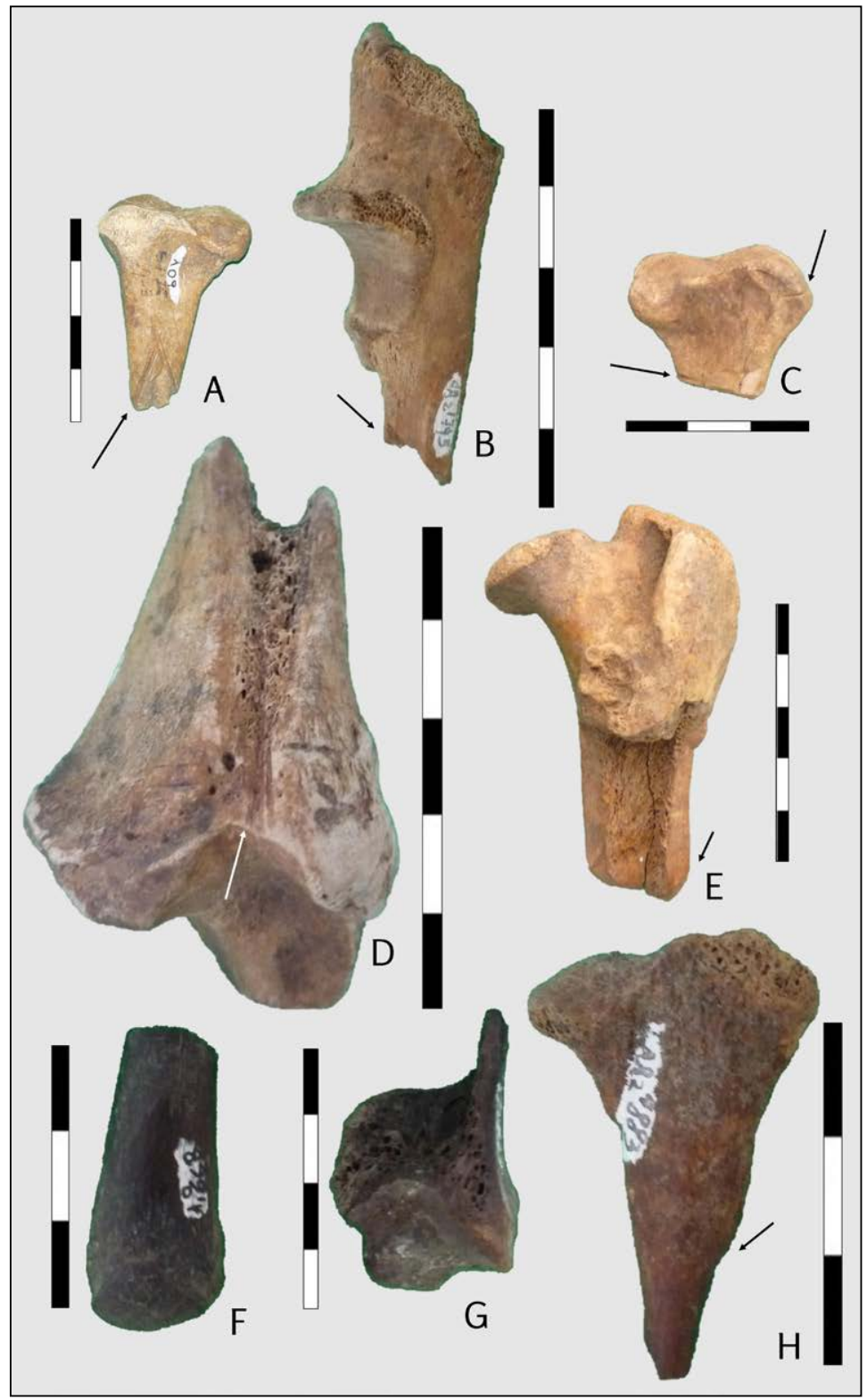

Figura 5. Alteraciones antrópicas: $A)$ radio proximal con aserrado en $X-B P-; B$ ) cúbito proximal con aserrado en $X$ y fractura oblicua $-C A-; C)$ radio proximal con aserrado perimetral $-C A-D$ ) tibia distal con aserrado en $X$ y fractura oblicua $-B P-; E$ ) fémur proximal con borde distal pulido-CA-; F) metapodio con quemado completo-CA-; G) tibia distal con quemado parcial y fractura longitudinal $-C A-; H)$ radio proximal con fractura transversal con superficie del hueso desbastado-CA-.

Asimismo, se registraron 12 especímenes de CA y cuatro de BP con alteración térmica, adoptando en todos los casos una coloración parduzca a negra que, en general, es interpretada como estadíos de quemado y carbonización (Frank, 2011; Lyman, 1994; Stiner y Kuhn, 1995). En CA, afectó de manera completa a una cara articular y un cuerpo de vértebra, y a dos fragmentos de metapodio (Figura 5F); y en forma parcial (una cara o un extremo del espécimen), a una vértebra, una esternebra, un cúbito proximal (con fractura transversal), una tibia distal (Figura 5G), una rótula, una falange y a un carpiano o tarsiano. En dos de los elementos fracturados, cúbito y metapodio, cuyos fragmentos remontaban, se observó también una alteración en la textura, ya que presentaban superficies suaves. En BP, se encontraron quemados una falange completa y, parcialmente, dos metapodios. 
En CA se identificaron fracturas antrópicas transversales vinculadas con aserrado en $X$ en un cúbito (Figura $5 B$ ) y un radio, con aserrado perimetral y con desbastado en dos radios, (Figuras $5 \mathrm{C}$ y $5 \mathrm{H}$, respectivamente). También se registraron fracturas: oblicuas en un radio con desbastado y en uno de los fémures pulidos; helicoidal en un fémur y una tibia, que también estaba quemada; longitudinal en el otro fémur pulido y en la tibia antes mencionada (Figura $5 \mathrm{G}$ ). En BP, se observó una fractura transversal en un radio con aserrado en $X$. Este aserrado también acompañó las fracturas oblicuas de dos radios proximales, y de un radio y una tibia distales. Se reconocieron fracturas helicoidales en un fémur y un húmero.

Debido a la presencia de aserrados y fracturas concordantes con la formatización de los huesos, se revisó el conjunto de instrumentos óseos. De este modo, se identificó como radio de carpincho el soporte óseo de una punta semi-acanalada de CA, cuya confección habría producido, como descarte, epífisis con aserrado en $\mathrm{X}$ y fracturas del hueso en estado fresco, como las indicadas en este registro (Figura 6).

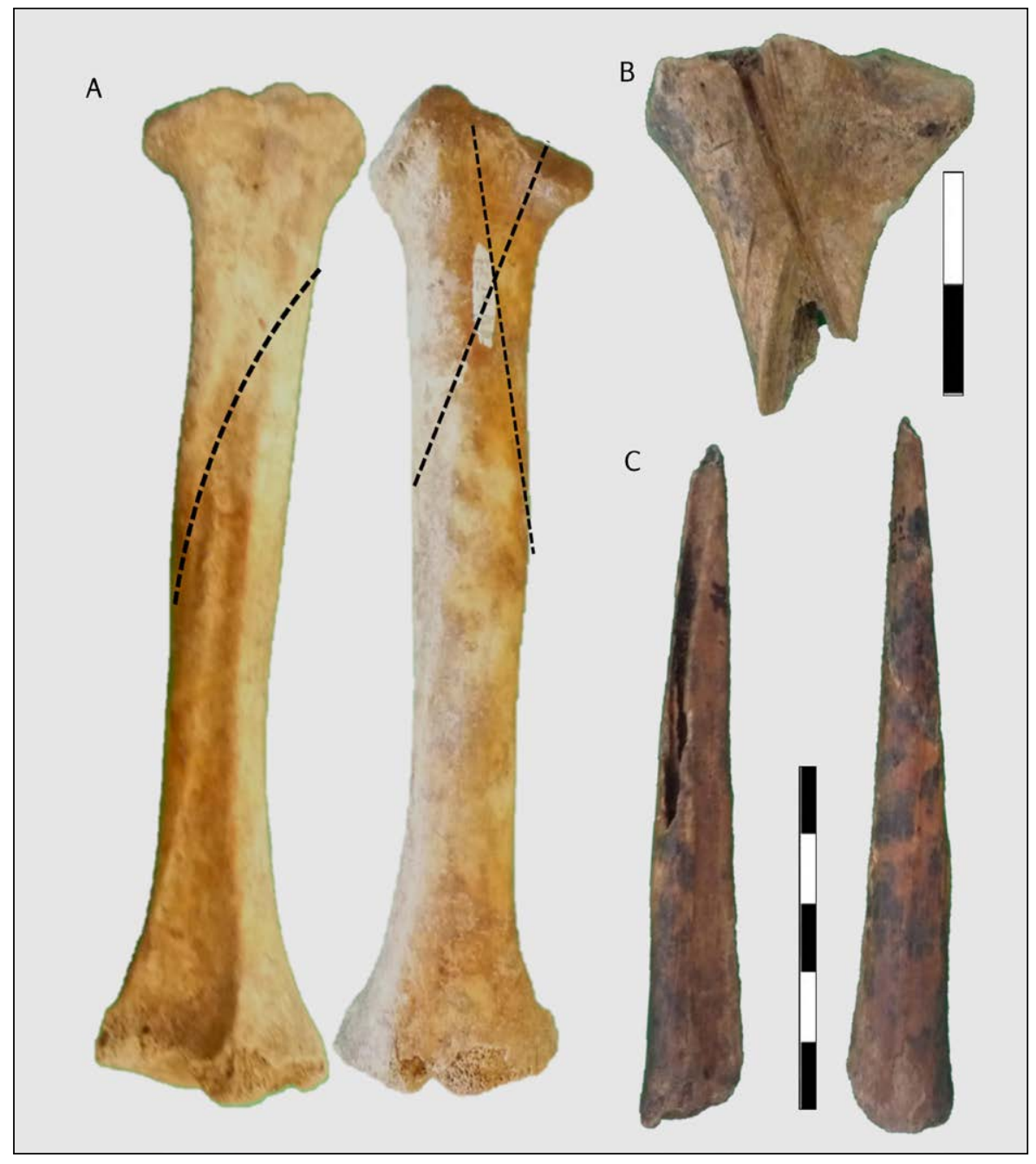

Figura 6. A) Radio de carpincho potencialmente utilizable como soporte óseo. Las líneas punteadas indican el sentido de los aserrados en $X$ que se registraron en esta unidad anatómica. B) Epífisis proximal de carpincho del sitio CA, descartada durante la confección de los instrumentos. C) Punta semi-acanalada del sitio CA, confeccionada sobre radio de carpincho. 


\section{Discusión}

La revisión y ampliación de la muestra analizada de los sitios BP y CA, permitió, en primera instancia, incrementar el conjunto identificado como Hydrochoerus hydrochaeris, tanto en términos de NISP como de MNE, y en el caso de BP, determinar, además, el MNI. Al contrastarlo con la totalidad del registro faunístico de cada sitio puede observarse que en $\mathrm{CA}$, donde hay un claro predominio de peces, la presencia de esta especie sería menos significativa, implicando $1,14 \%$ del NISP de vertebrados, mientras que en BP representa el 5,98\%. Respecto de la clase Mammalia, esta especie compone el $11,51 \%$ del NISP en el primer sitio, siendo el más abundante entre los mamíferos medianos/grandes (de un peso mayor a $10 \mathrm{~kg}$ ) y el $8,68 \%$ en el segundo, con una frecuencia similar a la de otros mamíferos grandes, por ejemplo, Blastocerus dichotomus (Tabla 1).

Si bien Hydrochoerus hydrochaeris tiene una presencia notable en los conjuntos, un MNI de 7 no estaría implicando cazas masivas como las descriptas en las fuentes etnohistóricas (Paucke, 2010 [1749-1767]). Esto sería esperable si se supone una cinegética que, compuesta de la secuencia herida con lanza -persecución en el aguaherida con maza (Paucke, 2010 [1749-1767]), implicaría una importante inversión de trabajo en la captura de cada individuo, ya sea que el animal se encontrara disperso o agrupado.

Si bien todas las regiones del esqueleto del carpincho se hallaron presentes en los dos sitios, implicando un ingreso de los animales enteros, y se contabilizó la misma cantidad de individuos, la representación anatómica en BP fue menor, principalmente respecto de las vértebras, costillas, esternebras, cinturas y autopodios. En ambos sitios, cráneo y mandíbulas, aunque moderadamente representados, se encontraban muy fragmentados. Esto podría estar vinculado con las actividades de caza en las que, como se menciona en las fuentes documentales, el animal era matado por un golpe sobre la cabeza, o de procesamiento -como la extracción del seso y lengua-. La presencia del esqueleto axial post-craneal es baja, lo cual podría relacionarse con una menor identificabilidad por la pérdida de rasgos diagnósticos, resultante de un procesamiento más intensivo de este segmento con alto contenido graso. En relación con esto, Mucciolo y Pérez Jimeno (2015) han señalado la presencia de fragmentos de reducido tamaño de tejido esponjoso (vertebral y articular) asignados a mamíferos indeterminados de CA. Así también, un reparto más extenso o un consumo diferido de las distintas partes del animal podrían haber generado una mayor dispersión de estos elementos. En este sentido, Pastor Arenas señala que "Muchas veces sólo se usa de inmediato la mitad de la presa; el resto se asa y se deseca para usarlo unos días después. Llegado el momento se somete al hervor para ablandarlo" (Arenas, 2003, p. 438). Aunque el autor no aclara si esta división sería simétrica (división en mitades longitudinales iguales) o jerarquizada (seleccionando partes), se señala una preferencia por unidades anatómicas con mayor contenido graso, por lo cual esta segmentación podría considerar diferencialmente las distintas porciones. Ya sea que se trate de un procesamiento más intenso o de una dispersión más extensa, estos comportamientos habrían afectado en mayor medida a BP, donde este roedor posee una mayor abundancia relativa.

En cuanto a los huesos largos del esqueleto apendicular, es destacable que las unidades anatómicas que tienen una mayor frecuencia son aquellas en las que se han registrado evidencias de su uso para la confección de instrumentos (radio, cúbito y fémur). Esto podría ser resultado de decisiones humanas que producirían un recorrido de procesamiento y descarte diferenciado de otras unidades anatómicas, o bien de una conservación diferencial debido a la densidad ósea de las mismas. En el primer caso estos elementos serían conservados, evitando un mayor procesamiento o su 
descarte durante una potencial limpieza del sitio. En el segundo, una mayor densidad ósea de éstos contribuiría a su mejor preservación, a la vez que los haría (además de su forma) soportes óseos adecuados para la manufactura. No obstante, no se cuenta con estudios de esta variable para Hydrochoerus hydrochaeris.

En lo que respecta a las evidencias del aprovechamiento antrópico de este recurso, se observaron marcas de corte que corresponderían a actividades de desarticulación de carcasas (en cráneo, mandíbulas, vértebras, acetábulo del iliaco, tróclea femoral, y en epífisis y caras articulares de huesos largos) y serían congruentes con el seccionamiento de la presa en las siguientes articulaciones: cabeza-cuello, costillacolumna, cintura pélvica-fémur, estilopodio-zeugopodio, zeugopodio-autopodio. Las marcas congruentes con actividades de descarne, como son los cortes longitudinales y oblicuos de los huesos largos, son escasas por lo que es probable que la carne fuera extraída luego de la cocción (De Nigris, 1999). Se atribuyen a actividades de cuereo la marca de raspado del cráneo y los cortes en huesos del autopodio. Las fracturas helicoidales en fémur y húmero podrían estar indicando la obtención de médula ósea de estas unidades anatómicas.

Los estadíos de alteración térmica observados se vincularían con una exposición al calor menor a los $400{ }^{\circ} \mathrm{C}$, de forma indirecta (p. ej., enterrado debajo del fuego) o poco prolongada (Frank, 2011; Lyman, 1994; Stiner y Kuhn, 1995). El uso de la primera no ha sido mencionado en fuentes documentales respecto del carpincho, y tampoco ha sido planteada en otros registros de mamíferos del área, por lo cual el segundo caso es más probable. Es poco claro si la extensión parcial sería resultado de una cobertura cárnea o de la reducción del contenido de materia orgánica en el hueso (es decir, por encontrarse en estado seco) al entrar en contacto con la fuente de calor (Cain, 2005; Lyman, 1994). El quemado completo de metapodio y falange, dado su escaso contenido cárneo, puede estar relacionado con la exposición al fuego de los elementos despellejados; vértebras y esternebras habrían sido descarnadas previamente, es decir, las mismas podrían haberse producido en distintos momentos entre la cocción y el descarte, aunque dada su escasez, no sería un resultado recurrente. Por lo tanto, es posible que utilizaran diferentes modos de cocción entre las que se incluirían el hervido o guisado, y el asado, tal como es planteado en las fuentes etnográficas consultadas (Paucke, 2010 [1749-1767]). Sin embargo, en estos sitios los recipientes cerámicos en muy pocos casos superaban los $20 \mathrm{~cm}$ de diámetro, por lo cual sólo permitirín la cocción de algunos segmentos del esqueleto del carpincho o con un trozamiento previo (Pérez Jimeno, 2007).

En cuanto a la presencia de marcas de aserrado en $\mathrm{X}$ y transversal (perimetral), desbastado o pulido en huesos largos - cúbito, radio, fémur y tibia - se interpretaron como resultado de una intencionalidad tecnológica. Teniendo en cuenta además el reconocimiento de una punta semi-acanalada confeccionada sobre un radio de carpincho, se considera que estos fueron utilizados como soporte para la confección de instrumentos óseos, principalmente los radios, ya que presentan estas marcas en forma recurrente y con características similares en ambos sitios.

Por lo expuesto puede evidenciarse como en el presente análisis se profundizó y rectificó la información sobre los perfiles anatómicos de esta especie. En trabajos anteriores se había señalado una predominancia, en CA, de partes esqueletarias de bajo rendimiento, como son cráneo, mandíbulas y huesos del autopodio, seguidos por escápula y húmero, de mayor rendimiento (Santiago, 2002). En consecuencia, se obtuvo una mejor representación del zeugopodio delantero y el fémur. En BP se registró el esqueleto axial post-craneal, las cinturas, cúbito, rótula, tibia y elementos del carpo y metacarpo que estaban considerados ausentes. Así también, se mejoró la identificación de modificaciones antrópicas, principalmente en BP, donde se reconocieron marcas 
de procesamiento, lo que permitió confirmar el aprovechamiento de este animal en dicho sitio, ya sugerido a partir de la alta frecuencia de especímenes y su utilidad económica (Pérez Jimeno, 2007). Por otra parte, la presencia de marcas vinculada a la confección de instrumentos y la identificación taxonómica de una punta evidenció el uso de estos huesos como materia prima en ambos sitios, lo cual era considerado probable aunque no estaba confirmado.

La disponibilidad de información más detallada de estos conjuntos permite contrastarlos con otros registros de Hydrochoerus hydrochaeris. En general, este taxa tiene una representación minoritaria en los conjuntos faunísticos de la llanura aluvial del Paraná medio. Son pocos los sitios donde supera el $1 \%$ del NISP total, siendo BP el que presenta el porcentaje más alto de este roedor (5,98\%), seguido por Paso del Tala (PT; $2,23 \%)$, Mini 1 (M1; $1,18 \%)$, CA (1,14\%), y Cerro Tapera Vázquez (CTV; $1 \%$ ), entre estos, sólo PT no registra alteraciones antrópicas (Barboza, 2014; Bonomo et al., 2010; Schmitz et al., 1972). Asimismo, en M1, al igual que en los sitios aquí analizados, se ha registrado el uso de huesos de carpincho con finalidad tecnológica (Buc, Mucciolo, Pérez Jimeno, Coll y De Luca, 2013; Pérez Jimeno, 2007). En la mayoría de los sitios de la región Hydrochoerus hydrochaeris se halla presente en una proporción menor (Tabla 4), y en algunos de ellos presenta evidencias de procesamiento (Los Bananos, Arroyo las Mulas y Las Tejas). Sólo en dos sitios este roedor está ausente (Río Salado Coronda y Campo Binaghi). Si bien este último se localiza a menos de $30 \mathrm{~km}$ de BP, el condicionante ambiental sería la causa más probable de dicha ausencia, ya que se encuentra en una zona más alta y abierta, en el límite de la llanura aluvial con el Chaco Húmedo, y su registro arqueofaunístico incluye además de especies propias del humedal, otras como las pertenecientes a la familia Dasypodidae (Burkart et al., 1999; Sartori y Pérez Jimeno, 2012). Resulta destacable también Puesto Fantín, localizado en

\begin{tabular}{|c|c|c|c|c|c|c|c|c|c|}
\hline \multirow{2}{*}{ Sitios } & \multirow{2}{*}{$\begin{array}{l}\text { NISP } \\
\text { total }\end{array}$} & \multicolumn{2}{|c|}{$\begin{array}{l}\text { Hydrochoerus } \\
\text { hydrochaeris }\end{array}$} & \multicolumn{4}{|c|}{ Región anatómica } & \multirow{2}{*}{ MA } & \multirow{2}{*}{$\begin{array}{c}\text { Referencia } \\
\text { bibliográfica }\end{array}$} \\
\hline & & NISP & $\%$ & $\mathrm{Cr}$ & PC & EZ & A & & \\
\hline Puesto Fantín & 1418 & 1 & 0,07 & & & $x$ & & & Santini, 2009 \\
\hline Cerro Aguará & 33123 & 378 & 1,14 & $x$ & $x$ & $\mathrm{x}$ & $x$ & $\mathrm{x}$ & \multirow{2}{*}{$\begin{array}{c}\text { Pérez Jimeno 2007; } \\
\text { Acosta et al. 2009; este trabajo }\end{array}$} \\
\hline Barrancas del Paranacito & 4364 & 261 & 5,98 & $x$ & $x$ & $x$ & $x$ & $x$ & \\
\hline Mini 1 & 2960 & 35 & 1,18 & \multicolumn{4}{|c|}{$S / D$} & $\mathrm{x}$ & Schmitz et al.,1972 \\
\hline Campo Binaghi & 565 & 0 & 0,00 & & & & & & Sartori y Pérez Jimeno, 2012 \\
\hline Los bananos & 2391 & 9 & 0,38 & \multicolumn{4}{|c|}{$S / D$} & $\mathrm{x}$ & Barboza y Martín, 2014 \\
\hline Paso del Tala & 1572 & 35 & 2,23 & $x$ & $x$ & $x$ & $x$ & & Barboza, 2014 \\
\hline El nene & 521 & 4 & 0,77 & & $x$ & & $x$ & & Barboza, 2016 \\
\hline La lechuza & 5575 & 3 & 0,05 & \multicolumn{4}{|c|}{$S / D$} & & Cornero et al., 2007 \\
\hline Arroyo Arenal 1 & 1613 & 2 & 0,12 & \multicolumn{4}{|c|}{$S / D$} & & Ottalagano, 2016 \\
\hline Arroyo Las Mulas 1 & 10134 & 30 & 0,30 & $x$ & & $x$ & $x$ & $x$ & Ottalagano, 2019 \\
\hline Las Palmeras & 469 & 3 & 0,64 & \multicolumn{4}{|c|}{$S / D$} & & Ottalagano et al., 2015 \\
\hline Río Salado Coronda & 215 & 0 & 0,00 & & & & & & \multirow{3}{*}{ Sartori, 2013} \\
\hline Las Tejas & 3497 & 12 & 0,34 & & & $x$ & $x$ & $\mathrm{x}$ & \\
\hline Pajas Blancas & 557 & 2 & 0,36 & & & $x$ & $x$ & & \\
\hline Cerro Tapera Vázquez & 1595 & 16 & 1,00 & $x$ & & $\mathrm{X}$ & $x$ & $x$ & Bonomo et al., 2010 \\
\hline
\end{tabular}

Tabla 4. Presencia/Ausencia de Hydrochoerus hydrochaeris en sitios arqueológicos de la llanura aluvial del Paraná medio. Se indica abundancia taxonómica (NISP y NISP\%); representación anatómica, para lo cual se segmentó el esqueleto, a partir de la distinción axial/apendicular y bajo/alto rendimiento económico, en cráneo (Cr), postcráneo (PC), estilopodio y zeugopodio (EZ) y autopodio (A); y modificaciones antrópicas (MA). 
el sector septentrional y cercano a CA, donde el carpincho está representado sólo por un húmero cuya presencia se debería a una selección y posterior consumo, resultado de capturas circunstanciales (Santini, 2009). En una escala espacial más amplia, ha sido señalado que la frecuencia del carpincho en los conjuntos de mamíferos, si bien es baja, resulta más significativa en la llanura aluvial del Paraná medio, particularmente en el sector septentrional, que en el tramo inferior y en los abanicos aluviales del Chaco oriental (Servin, 2016). En el primer caso se ha planteado la hipótesis de una restricción simbólica sobre la especie (Loponte, 2008).

\section{Consideraciones finales}

El estudio aquí realizado contribuye a una mejor comprensión del rol que habría jugado el carpincho para las poblaciones humanas que habitaron los sitios CA y BP en el pasado. El mismo habría sido muy valorado económicamente, ya que habría aportado recursos alimenticios (carne, vísceras, médula y grasa), y materias primas derivadas, como son los huesos y probablemente el cuero. Respecto de este último producto, resulta impreciso qué características habría tenido su obtención, ya que si bien en el presente es importante su explotación peletera de acuerdo a procedimientos como los señalados en trabajos actualísticos realizados sobre coipo (Escosteguy, 2014), en las fuentes documentales el cuero se separa de la carne luego de su cocción (Paucke, 2010 [1749-1767]). De este modo, se destacan BP y en menor medida CA, respecto de otros sitios de la llanura aluvial del Paraná medio, ya que presentan abundancia relativa mayor al $1 \%$, completitud anatómica y evidencias de procesamiento antrópico vinculadas a su uso alimentario y tecnológico. En el caso de Mini 1, en el cual también se evidencia la confección de instrumentos, es probable que presente características similares, aunque no se encontró en la bibliografía información que permita contrastar la representación anatómica y marcas de procesamiento (Buc et al., 2013; Pérez Jimeno 2007; Schmitz et al., 1972).

Es posible que las diferencias en la representación de esta especie (en términos de abundancia, perfiles anatómicos y presencia de alteraciones antrópicas) se vinculen con la dispersión resultante del consumo diferido o la pérdida de rasgos diagnósticos, derivadas del procesamiento. En consecuencia, es preciso abordarla, reconociendo diferencias en la preparación y consumo para distintos mamíferos y entre distintas poblaciones. Para ello, la producción de más información para la región y con mayor grado de detalle resulta indispensable.

\section{Agradecimientos}

A la Dra. Laura Pérez Jimeno por haberme orientado en la realización de este trabajo y a la Dra. Julieta Sartori por las valiosas observaciones y sugerencias realizadas. Así también agradezco a los evaluadores, cuyas correcciones y recomendaciones contribuyeron a la mejora del manuscrito presentado. No obstante, todo lo expuesto es absoluta responsabilidad de la autora. 


\section{Q Referencias bibliográficas}

》Acosta, A., Escudero, S., Feuillet Terzaghi, R., Loponte, D. y Pérez Jimeno, L. (2009). Conectando registros: variabilidad arqueológica en la cuenca del Paraná. En M. Berón, L. Luna, M. Bonomo, C. Montalvo, C. Aranda y M. Carrera Aizpitarte (Eds.), Mamul Mapü: pasado y presente desde la arqueología pampeana (Tomo 2, pp. 17-28). Buenos Aires: Libros del Espinillo.

»Arenas, P. (2003). Etnografía y alimentación entre los toba-ñachilamoleek y wichí lhuku'tas del Chaco Central (Argentina). Buenos Aires: Del autor.

» Barboza, M. (2014). Análisis arqueofaunístico del sitio Paso del Tala. Revista del Museo de Antropología,7(2), 219-226. DOI: https://doi.org/10.31048/1852.4826.v7.n2.9171.

» Barboza, M. (2016). Ocupaciones prehispánicas en la margen izquierda del Paraná medio (Goya, Corrientes, Argentina). Análisis zooarqueológico. Intersecciones en Antropología, Volumen Especial 3, 57-69.

» Barboza, M. y Martín, M. (2014). Análisis del registro aarqueofaunístico de grupos cazadores recolectores del Holoceno tardío de la llanura aluvial del Paraná medio (sitio Los Bananos, departamento Goya, Corrientes, Argentina). Revista chilena de Antropoligía, 29(1), 136-140. DOI: $10.5354 / 0719-1472.2015 .36221$

" Behrensmeyer, A. (1978). Taxonomic and ecological information from bone weathering. Paleobiology, 4(2), 150-162.

» Binford, L. R. (1981). Bones. Ancient men and modern myths. Nueva York: Academic press.

» Binford, L. R. (1984). Faunal remains from Kasies river mouth. Orlando: Academic press.

» Bode, F., Cao, J., Resoagli, J., Fernández, J.y Llano Laiseca, E. (2014). Descripción anatómica del esqueleto apendicular del carpincho (Hydrochoerus hydrochaeris). Revista veterinaria, 25(1), 21-26. DOI: 10.30972/vet.251544

» Bode, F., Fernández, J., Cao, J. y Resoagli, J. (2013). Descripción del esqueleto axial del carpincho (Hydrochoerus hydrochaeris). Revista veterinaria, 24(1), 44-46. DOI: 10.30972/vet.2411149

» Bonomo, M., Colobig, M., Passegi, E., Zucol, A., y Brea, M. (2010). Multidisciplinary studies at Cerro Tapera Vázquez site, pre-delta National Park, Argentina: the archaeological, sedimentological and palebotanical evidence. Quaternary International, 245(1), 48-61. DOI: 10.1016/j.quaint.2010.11.018

» Buc, N., Mucciolo, L., Pérez Jimeno, L., Coll, M. y De Luca, S. (2013). Series experimentales en obtención de formas base para la confección de instrumentos óseos en la cuenca del Paraná medio e inferior. Cuadernos del Instituto Nacional de Antropología y Pensamiento Latinoamericano, 1(2), 185 - 199.

» Burkart, A., Bárbaro, N., Sánchez, R. y Gómez, D. (1999). Ecorregiones de la Argentina. Administración de parques nacionales. Programa de desarrollo Institucional ambiental. Buenos Aires: Secretaria de recursos naturales y desarrollo sustentable.

» Cain, C. (2005). Using burned animal bone to look at Middle Stone Age occupation and behavior. Journal of Archaeological Science, 32, 873-884. DOI: 10.1016/j.jas.2005.01.005

» Cordiviola, E., Giraudo, A., Lajmanovich, R., Beltzer, A. y Sottini, A. (2001). Ficha informativa de los humedales Ramsar: Jaaukanigás. Santo Tomé: Instituto Nacional de Limnología.

» Cornero, S., Solomita, F. y Curetti, P. (2007). Componente arqueofaunísitco del sitio La Lechuza (provincia de Santa Fe). En F. Oliva, y N. D. Rodriguez (Eds.), Arqueología argentina en los inicios de un nuevo siglo, Publicación del XIV Congreso Nacional de Arqueología Argentina (Tomo I, pp. 167-174). Rosario: Laborde editores.

» Corriale, M. (2010). Uso y selección de hábitat de carpincho a distintas escalas espacio temporales. (Tesis Doctoral inédita), Universidad de Buenos Aires, Argentina. 
»De Nigris, M. (1999). Lo crudo y lo cocido: sobre los efectos de la cocción en la modificación ósea. Arqueología, 9, 239-264.

»Escosteguy, P. (2014). Estudios etnoarqueológicos con cazadores de coipo de Argentina. Antípoda, 20, 145-165. DOI: 10.7440/antipoda20.2014.07

»Felix , G., De Lima Almeida Paz, I., Piovezan, U., García, R., Pinhero, M., Mendes Fernandes, A., Oliveira Lima, K. y Rezende, M. (2014). Características de carne y de las canales de capibaras (Hydrochoerus hydrochaeris) en vida libre. Nacameh, 8(1), 22-38.

»Frank, A. (2011). Tratamiento térmico y manejo del fuego en sociedades cazadoras-recolectoras de la Meseta Central de Santa Cruz. (Tesis Doctoral inédita), Universidad Nacional de La Plata, Argentina.

» González Jiménez, E. (1995). El capibara (Hydrochoerus hydrochoeris). Estado actual de su producción. Roma: Organización de las Naciones Unidas para la Agricultura y la Alimentación.

» Grayson, D. (1984). Quantitative zooarchaeology. Topics in the analysis of archaeological faunas. Orlando: Academic Press.

» Iriondo, M., Paggi, J. y Parma, M. (2007). The middle Parana river. Limnology of a subtropical wetland. Verlag: Springer.

" Linnaeus, C. (1766). Systema naturae per regna tria naturae, secundum classes, ordines, genera, species, cum characteribus, differnetiis, synonymis, locis. Estocolmo: Savius.

» Loponte, D. (2008). Arqueología del Humedal del Paraná inferior (bajíos ribereños meridionales). Buenos Aires: Ediciones del Riel.

» Lyman, R. L. (1994). Vertebrate taphonomy. Nueva York: Cambridge Universisty press. DOI: $10.1017 /$ СВ09781139878302

» Lyman, R. L. (2008). Quantitative paleozoology. Nueva York: Cambridge University Press.

» Martín, M. (2015). Análisis zooarqueológico en el sudoeste de Corrientes: sitios Los Bananos. Holoceno tardío. (Tesis de Licenciatura inédita), Universidad Nacional de Rosario, Argentina.

» Mengoni Goñalons, G. L. (1999). Cazadores de guanacos de la estepa patagónica. Buenos Aires: Sociedad Argentina de Antropología.

» Mengoni Goñalons, G. (2010). Zooarqueología en la práctica: algunos temas metodológicos. Xama, 19-23, 83-113.

" Mucciolo, L. y Pérez Jimeno, L. (2015). Patrones de consumo final de cérvidos en el Paraná medio: el caso del sitio Cerro Aguará. Revista del Museo de Antropología, 8(1), 79-90. DOI: 10.31048/1852.4826.v8.n1.11460

» Musali, J. y Pérez Jimeno, L. (2016). La pesca entre cazadores-recolectores del Paraná medio durante el Holoceno tardío. El caso del sitio Cerro Aguará (provincia de Santa Fe). Cuadernos del Instituto Nacional de Antropología y Pensamiento Latinoamericano, 25(1), 1-17.

»Ottalagano, F. (2016). Investigaciones arqueológicas en el sitio Arroyo Arenal I: Cuenca media del río Paraná (Entre Ríos, Argentina). Cuadernos del Instituto Nacional de Antropología y Pensamiento Latinoamericano, 25(2), 159-176.

» Ottalagano, F. (2019). Estudios zooarqueológicos en la cuenca media del Paraná: sitio Arroyo Las Mulas 1 (Entre Ríos, Argentina). Mundo de Antes, 13(1), 59-84.

» Ottalagano, F., Darigo, M., Pereyra, B., Brancatelli, C. y lannelli, L. (2015). Investigaciones arqueológicas en el sitio La Palmera 2 (cuenca del Paraná medio, provincia de Entre Ríos, Nordeste de Argentina). Revista de Antropología del Museo de Entre Ríos, 1(1), 55-65.

» Paucke, F. (2010 [1749-1767]). Hacia allá y para acá. Santa Fe: Espacio santefesino.

»Pérez Jimeno, L. (1996). Análisis arqueofaunístico del sitio Barrancas del Paranacito. Florencia. Departamento General Obligado (Pcia. de Santa Fe). (Tesis de Licenciatura inédita), Universidad Nacional de Rosario, Argentina.

» Pérez Jimeno, L. (2007). Investigaciones arqueológicas en el sector septentrional de la llanura aluvial del Paraná -maergen santafesina-: la variabilidad del registro arqueológico. (Tesis Doctoral inédita), Universidad Nacional de La Plata, Argentina. 
»Pérez Jimeno, L. (2008). Presencia y utilización de moluscos de agua dulce en un sitio del humedal paranaense. Revista de la Escuela de Antropología, 14, 25-32.

»Pérez Jimeno, L. (2009). Los recursos ictícolas en el Holoceno tardío en un sitio del humedal Paranaense - Florencia, Santa Fe, Argentina-. La arqueología como profesión: los primeros 30 años. XI Congreso Nacional de Arqueología Uruguaya (pp. 731-744). Montevideo: Asociación Uruguaya de Arqueología.

»Pérez Jimeno, L. y Servin, A. (2017). Aproximación al aprovechamiento de aves en el humedal del Paraná: Cerro Aguará como caso de estudio. Revista de Antropología del Museo de Entre Ríos, 3(2), 67-84.

» Píccoli, C., Martín, M. y Barboza, C. (2017). El registro arqueofaunístico del subtramo Norte de la margen izquierda del Paraná Medio (Corrientes, Argentina). Arqueología, 23(3), 35-63. DOI: 10.34096/arqueologia.t23.n3.4007

»Quintana, R. (1996). Análisis y evaluación de la aptitud de hábitat del carpincho (Hydrochoerus hydrochaeris) en relacion con la heterogeneidad del paisaje y las interacciones con ganado doméstico. (Tesis Doctoral inédita), Universidad de Buenos Aires, Argentina.

»Quiroga Tapias, G. y Garcia Niño, I. (2014). Evaluación de rendimientos en chiguiros (Hydrochoerus hydrochaeris). En H. López Arévalo, P. Sánchez Palomino, y O. Montenegro (Eds.), El chigüiro (Hydrochoerus hydrochaeris) en la Orinoquía colombiana: Ecología, manejo sostenible y conservación (pp. 383-396). Bogotá: Universidad Nacional de Colombia.

"Santiago, F. (2002). Los roedores en el "menú" de los habitantes de Cerro Aguará (Pcia. de Santa Fe): el análisis arqueofaunístico. (Tesis de Licenciatura inédita), Universidad Nacional de Rosario, Argentina.

»Santini, M. (2009). Prehistoria de la región meridional del Gran Chaco. aportes del análisis de restos faunísticos en la reconstrucción de las estrategias adaptativas de los grupos aborígenes. (Tesis Doctoral inédita), Universidad Nacional de La Plata, Argentina.

»Sartori, J. (2013). Variabilidad del registro arqueofaunístico de la cuenca media e inferior del rio Coronda (margen derecha, provincia de Santa Fe). Análisis desde una perspectiva integral. (Tesis Doctoral inédita), Universidad Nacional de Rosario, Argentina.

»Sartori, J. (2015). La información etnográfica y etnológica como marco interpretativo para contextos zooarqueológicos en la Llanura Aluvial del Paraná (Santa Fe, Argentina). Revista del Museo de Antropología, 8(2), 77-90. DOI: 10.31048/1852.4826.v8.n2.11854.

» Sartori, J. y Pérez Jimeno, L. (2012). Zooarqueología en la llanura aluvial del Paraná: el sitio Campo Binaghi desde una perspectiva regional. Comechingonia. Revista de arqueología, 16(2), 93-113. DOI: 10.37603/2250.7728.v16.n2.17990

» Schmitz P., Ceruti, C., González, A. y Rizzo, A. (1972). Investigaciones arqueológicas en la zona de Goya (Corrientes), Argentina. Dédalo, 15, 11-121.

» Servin, A. (2016). Variabilidad en la presencia de carpincho (Hydrochoerus hydrochaeris) en sitios arqueológicos vinculados a la cuenca del Paraná, en su tramo medio e inferior. Anuario de Arqueología, 8, 101-112.

»Stiner, M. C. y Kuhn, S. (1995). Differential burning, recrystallization and fragmentation of archaeological bone. Journal of Archaeological Science, 22, 223-237. DOI: 10.1006/ jasc. 1995.0024 